\title{
Letter to the Editor: Comment on "Gabapentinoid Benefit and Risk Stratification: Mechanisms Over Myth"
}

\author{
Alyssa M. Peckham (D) · Jordan R. Covvey (D) · Kirk E. Evoy (D)
}

Received: August 24, 2020 / Accepted: November 19, 2020 / Published online: February 9, 2021

(c) The Author(s) 2021

\section{Key Summary Points}

This letter was written in response to

"Gabapentinoid Benefit and Risk

Stratification: Mechanisms Over Myth" as

a large body of evidence exists supporting the potential for gabapentinoid abuse that was overlooked in the named article.

A. M. Peckham ( $\square)$

Bouvé College of Health Sciences, School of

Pharmacy, Northeastern University, Boston, MA,

USA

e-mail: a.peckham@northeastern.edu

A. M. Peckham

Department of Pharmacy, Massachusetts General

Hospital, Boston, MA, USA

J. R. Covvey

Duquesne University School of Pharmacy,

Pittsburgh, PA, USA

K. E. Evoy

The University of Texas at Austin College of

Pharmacy, Austin, TX, USA

K. E. Evoy

University Health System, San Antonio, TX, USA

K. E. Evoy

The University of Texas Health San Antonio School

of Medicine, San Antonio, TX, USA
This letter was written to bridge the knowledge gap not addressed by the authors related to the significant, original research evidence that supports gabapentinoid abuse.

The authors argue that gabapentinoids are overwhelmingly safe, which may be true for some populations, but not all.

\section{DIGITAL FEATURES}

This article is published with digital features, including a summary slide, to facilitate understanding of the article. To view digital features for this article go to https://doi.org/10.6084/ m9.figshare.12994247.

To the Editor,

We recently read with concern the article entitled "Gabapentinoid benefit and risk stratification: mechanisms over myth," published by McAnally and colleagues [1]. While we agree that gabapentinoids have important therapeutic roles and represent a relatively low-risk option for many patients, we believe this paper fails to accurately characterize the significant body of evidence identifying misuse/abuse associated with these medications. In particular, 
the assertions that gabapentinoids are "remarkably safe" and that the literature is "sensationalized" and fraught with "liberal conjecture" [1] is a personal opinion, and an inaccurate representation of the current literature. We concur that the mechanism of these medications (both therapeutically and abuse-related) is not fully elucidated. However, significant evidence exists from many different sources describing misuse/ abuse that cannot be overlooked. A simple search of MEDLINE yields more than 100 articles describing original research into gabapentinoid misuse, abuse or overdose, with the vast majority finding evidence that this is indeed occurring, and the problem is growing. Furthermore, recent evidence of their misuse potential has led the UK to re-classify both gabapentinoids as controlled substances [2]. Several US states have taken congruent measures for gabapentin, with the US Food and Drug Administration (FDA) considering similar regulation [3, 4].

The authors downplay the potential for misuse/abuse by stating there is little documented evidence of true physiologic addiction to the gabapentinoids in the literature [1]. While this may be true, the evidence clearly shows that these medications can produce desirable effects that may motivate a person to misuse or abuse them. A plethora of studies of persons misusing/abusing gabapentinoids describe pleasurable effects, including euphoria, marijuana-like highs, alcohol-like intoxication, improved sociability, increased energy and other effects akin to medications commonly abused, whereas many others describe concurrent use with opioids or other psychoactive compounds as a means to enhance their desirable effects as primary motivations for use $[5,6]$. Blinded studies have identified that gabapentinoids produce similar drug-liking effects to diazepam [7] and tetrahydrocannabinol (the psychoactive component of cannabis) [8] in patients with a history of substance use disorder. The authors also state that studies indicate that the "vast majority of misuse events appear to occur in an attempt to ameliorate opioid withdrawal symptoms" [1], which is simply not borne out in the current literature. Several studies have assessed motivators for gabapentinoid use. One found attenuation of opioid withdrawal symptoms as the most common reason, endorsed by $67 \%$ of respondents, but found abuse indicators such as synergism with other substances (52\%), recreation (47\%) and curiosity (41\%) reported in similar magnitude [9]. Another found that gabapentin made the respondent feel intoxicated in $76 \%$ of cases, while also helping to relieve pain (76\%), withdrawal (70\%), anxiety (63\%), sleep problems (69\%) and low mood (58\%) [10]. While we agree relief of withdrawal symptoms is a common reason for use, more than half of respondents endorse other abuse or misuse indicators as key reasons for use $[9,10]$.

The authors also discount or fail to include pertinent epidemiologic data. For instance, while they note that 600 cases of gabapentinoid misuse reported to the US FDA Adverse Event Reporting System (FAERS) is low, there is no mention of a similar study of the European Medicine Agency (EMA) database which reported nearly 12,000 cases from 2004-2015, with more than $75 \%$ of those reported having occurred from 2012-2015 [11]. Additionally, in one of the largest studies of gabapentinoid abuse to date, US commercial insurance claims data revealed that gabapentin and pregabalin displayed similar patterns of abuse liability compared to benzodiazepines and Z-hypnotics [12]. The authors cited this study but criticized the methodology of this article, namely the use of Lorenz-1 curves as an economic measure of inequity of distribution of income and goods. However, this methodology is prevalent in pharmacovigilance research as a means of elucidating non-medical use or abuse of medications [13-15].

The authors also describe that the benefits of gabapentinoid therapy far outweigh the risks [1]. While we concur this is true for many patients, it may not be the case for all. As mentioned, gabapentin is primarily used off-label, but outside of neuropathic pain conditions, very few off-label indications have strong evidence to support its efficacy [16]. However, studies describing increased patient harm associated with gabapentinoids, particularly when used alongside opioids, have proliferated. This is especially concerning given that as many as 
$50-60 \%$ of patients prescribed gabapentinoids may also be prescribed opioids $[4,17,18]$. As the US continues to experience record numbers of opioid overdose fatalities, such risks of additive therapies cannot be ignored. While the authors did provide limited acknowledgement of the increased risk among patients concurrently using opioids and gabapentinoids, they failed to expand on the relevant evidence in this area. Large-scale, population-based studies have recently identified that gabapentinoids, when used concomitantly with opioids, significantly increase all-cause, drug-related and respiratory depression-related hospital utilization $[19,20]$, risk of neonatal opioid withdrawal [21, 22] and, most concerning, risk of opioid-related mortality [18, 23-27]. Such studies prompted the FDA to add new warnings of respiratory depressant effects to the gabapentinoid product labeling and call for manufacturers to conduct clinical trials regarding their abuse potential [28].

We acknowledge the important role gabapentinoids play in treating a variety of medical conditions and are not calling for sweeping reductions in their use. When used appropriately under the guidance of healthcare professionals, these represent relatively safe medication options for most patients. However, there is significant evidence that these medications are being misused outside of medical recommendations $[5,6,9,10]$, often in excess of FDA recommended doses [12], and obtained from non-regulated sources [5]. As pharmacist clinicians, it is our professional responsibility to understand and educate healthcare professionals and the public alike on the delicate balance of safety/efficacy of pharmacologic treatments. There is sufficient evidence to warrant caution when prescribing gabapentinoids, and this caution should be heightened among patients with an opioid use disorder or those who concurrently use high-dose opioids, especially with other central nervous system depressants. This article, while communicating several useful points, more properly should be labeled as a commentary as opposed to a literature review.

\section{ACKNOWLEDGEMENTS}

Funding. No funding or sponsorship was received for this study or publication of this article.

Authorship. All named authors meet the International Committee of Medical Journal Editors (ICMJE) criteria for authorship for this article, take responsibility for the integrity of the work as a whole, and have given their approval for this version to be published.

Disclosures. Alyssa Peckham, Jordan Covvey, and Kirk Evoy declare that they have no conflict of interest.

Compliance with Ethics Guidelines. This article is based on previously conducted studies and does not contain any studies with human participants or animals performed by any of the authors.

Peer Review. Please note, contrary to the journal's standard single-blind peer review process, as a commentary this article underwent review by a member of the journal's Editorial Board.

Open Access. This article is licensed under a Creative Commons Attribution-NonCommercial 4.0 International License, which permits any non-commercial use, sharing, adaptation, distribution and reproduction in any medium or format, as long as you give appropriate credit to the original author(s) and the source, provide a link to the Creative Commons licence, and indicate if changes were made. The images or other third party material in this article are included in the article's Creative Commons licence, unless indicated otherwise in a credit line to the material. If material is not included in the article's Creative Commons licence and your intended use is not permitted by statutory regulation or exceeds the permitted use, you will need to obtain permission directly from the copyright holder. To view a copy of this licence, visit http://creativecommons.org/licenses/by$\mathrm{nc} / 4.0 /$. 


\section{REFERENCES}

1. McAnally H, Bonnet U, Kaye AD. Gabapentinoid benefit and risk stratification: mechanisms over myth. Pain Ther. 2020;9:441-52. https://doi.org/10. 1007/s40122-020-00189-x.

2. Burns C. Pregabalin and gabapentin to be reclassified as Class $\mathrm{C}$ controlled substances. The Pharmaceutical Journal. 2018. https://www.pharmac eutical-journal.com/news-and-analysis/news/prega balin-and-gabapentin-to-be-reclassified-as-class-c-co ntrolled-substances/20205611.article. Accessed 3 May 2020.

3. Peckham AM, Ananickal MJ, Sclar DA. Gabapentin use, abuse, and the US opioid epidemic: the case for reclassification as a controlled substance and the need for pharmacovigilance. Risk Manag Healthc Policy. 2018;11(1):109-16.

4. Throckmorton DC, Gottlieb S, Woodcock J. The FDA and the next wave of drug abuse-proactive pharmacovigilance. N Engl J Med. 2018;379:205-7.

5. Evoy KE, Morrison MD, Saklad SR. Abuse and misuse of pregabalin and gabapentin. Drugs. 2017;77(4):403-26.

6. Smith RV, Havens JR, Walsh SL. Gabapentin misuse, abuse and diversion: a systematic review. Addiction. 2016;111(7):1160-74.

7. Pfizer. Lyrica (pregabalin) capsules and oral solution [full prescribing information]. New York: Pfizer; 2016.

8. Lile JA, Wesley MJ, Kelly TH, Hays LR. Separate and combined effects of gabapentin and [INCREMENT]9-tetrahydrocannabinol in humans discriminating [INCREMENT]9-tetrahydrocannabinol. Behav Pharmacol. 2016;27:215-24.

9. Snellgrove BJ, Steinert T, Jaeger S. Pregabalin use among users of illicit drugs: a cross-sectional survey in southern Germany. CNS Drugs. 2017;31(10): 891-8.

10. Applewhite D, Regan S, Koenigs K, Mackin S, Schmidt C, Wakeman SE. Use of promethazine, gabapentin and clonidine in combination with opioids or opioid agonist therapies among individuals attending a syringe service program. Int J Drug Policy. 2020;79:102752.

11. Chiappini S, Schifano F. A decade of gabapentinoid misuse: an analysis of the European Medicines Agency's "Suspected Adverse Drug Reactions" database. CNS Drugs. 2016;30(7):647-54.
12. Peckham AM, Fairman KA, Sclar DA. Prevalence of gabapentin abuse: comparison with agents with known abuse potential in a commercially insured US population. Clin Drug Investig. 2017;37(8): 763-73.

13. Hallas J, Støvring H. Templates for analysis of individual-level prescription data. Basic Clin Pharmacol Toxicol. 2006;98(3):260-5.

14. Birt J, Johnston J, Nelson D. Exploration of claimsbased utilization measures for detecting potential nonmedical use of prescription drugs. J Manag Care Spec Pharm. 2014;20(6):639-46.

15. Perini E, Junqueira DRG, Lana LGC, Luz TCB. Prescription, dispensation and marketing patterns of methylphenidate. Rev Saude Publica. 2014;48(6): 873-80.

16. Goodman CQ, Brett AS. A clinical overview of offlabel use of gabapentinoid drugs. JAMA Intern Med. 2019;179(5):695-701.

17. Pauly NJ, Delcher C, Slavova S, et al. Trends in gabapentin prescribing in a commercially insured U.S. adult population, 2009-2016. J Manag Care Spec Pharm. 2020;26(3):246-52.

18. Torrance N, Veluchamy A, Zhou Y, et al. Trends in gabapentinoid prescribing, co-prescribing of opioids and benzodiazepines, and associated deaths in Scotland. Br J Anaesth. 2020;125(2):159-67.

19. Peckham AM, Fairman KA, Sclar DA. All-cause and drug-related medical events associated with overuse of gabapentin and/or opioid medications: a retrospective cohort analysis of a commercially insured US population. Drug Saf. 2018;41(2):213-28.

20. Daly C, Griffin E, Ashcroft DM, Webb RT, Perry IJ, Arensman E. Intentional drug overdose involving pregabalin and gabapentin: findings from the National Self-Harm Registry Ireland, 2007-2015. Clin Drug Investig. 2018;38(4):373-80.

21. Loudin S, Murray S, Prunty L, Davies T, Evans J, Werthammer J. An atypical withdrawal syndrome in neonates prenatally exposed to gabapentin and opioids. J Pediatr. 2017;181:286-8.

22. Huybrechts KF, Bateman BT, Desai RJ, et al. Risk of neonatal drug withdrawal after intrauterine co-exposure to opioids and psychotropic medications: cohort study. BMJ. 2017;358:j3326.

23. Gomes T, Juurlink DN, Antoniou T, et al. Gabapentin, opioids, and the risk of opioid-related death: a population-based nested case-control study. PLoS Med. 2017;14(10):e1002396. 
24. Gomes T, Greaves S, van den Brink W, Antoniou T, Mamdani MM. Pregabalin and the risk of opioidrelated death: a nested case-control study. Ann Intern Med. 2018;169(10):732-4.

25. Abrahamsson T, Berge J, Öjehagen A, Håkansson A. Benzodiazepine, z-drug and pregabalin prescriptions and mortality among patients in opioid maintenance treatment-a nation-wide registerbased open cohort study. Drug Alcohol Depend. 2017;174:58-64.

26. Macleod J, Steer C, Tilling K, et al. Prescription of benzodiazepines, z-drugs, and gabapentinoids and mortality risk in people receiving opioid agonist treatment: observational study based on the UK
Clinical Practice Research Datalink and Office for National Statistics death records. PLoS Med. 2019;16(11):e1002965.

27. Molero Y, Larsson H, D'Onofrio BM, Sharp DJ, Fazel $\mathrm{S}$. Associations between gabapentinoids and suicidal behaviour, unintentional overdoses, injuries, road traffic incidents, and violent crime: population based cohort study in Sweden. BMJ. 2019;365: j2147.

28. FDA In Brief: FDA requires new warnings for gabapentinoids about risk of respiratory depression. https://www.fda.gov/news-events/fda-brief/fda-brieffda-requires-new-warnings-gabapentinoids-aboutrisk-respiratory-depression. Accessed 20 Aug 20. 